\section{Excavaciones Arqueológicas en la catedral de Tarragona (2000-2002)}

Josep Maria Macias, Joan Menchon, Andreu Muñoz, IMMACULADA TEIXELL

\begin{abstract}
Resumen
El Plan Director de la Catedral de Tarragona es una ambiciosa programación de los trabajos de conservación-restauración que se han de llevar a cabo en este monumento de la ciudad. Entre éstos está el estudio histórico y arqueológico del conjunto, más cuando la catedral se asienta sobre una de las terrazas del complejo imperial del Concilium Prouinciae Hispaniae Citerioris, donde en la antigüedad tardía se estableció el episcopio visigótico. Este espacio se recupera tras la restauración efectiva de la sede arzobispal, en el siglo XII, y es el germen de la actual sede eclesiástica.

Este artículo es una primera aproximación a la evolución arquitectónica de una zona de la catedral de Tarragona, al norte del claustro, que se ha podido estudiar gracias a la inversión económica derivada del convenio entre el Cabildo de la Catedral de Tarragona, Ayuntamiento, Diputación, Consell Comarcal del Tarragonès y Generalitat de Catalunya.
\end{abstract}

Palabras clave: Catedral, claustro, época romana, época medieval, épocas moderna y contemporánea.

\begin{abstract}
The Tarragona Cathedral Director Plan is an ambitious scheme for conservation and restoration work to be carried out on this city landmark. Works include the historical and archaeological study of the property, all the more interesting for the cathedral's position on one of the terraces of the imperial complex of the Consilium Prouinciae Hispaniae Citerioris, where in late antiquity the Visigoth episcopacy was established. This area was recovered during the restoration of the archiepiscopal see in the $12^{\text {th }}$ century, and is the origin of the present ecclesiastical see.

This article is a first approach to the architectural evolution of an area of the Cathedral of Tarragona, the north of the cloister, which it has been possible to study with the help of economic investment derived from the agreement between the chapter of Tarragona Cathedral, the city council, the county council, the regional council of Tarragona and the Catalan autonomous government.
\end{abstract}

Key words: Cathedral, cloister, Roman era, medieval era, modern and contemporary eras.
Es indudable que la catedral es el edificio histórico más importante de la Tarragona medieval. Sus características arquitectónicas, evolución y su especial ubicación en el centro del antiguo recinto sagrado romano la convierten en un monumento de especial interés para comprender, no sólo la ciudad medieval y moderna, sino también la Tarraco romana y la Terracona de la antigüedad tardía.

Los trabajos derivados del Plan Director de la Catedral de Tarragona, coordinados por los arquitectos Joan Figuerola y Joan Gavaldà, han permitido una aproximación a la evolución del conjunto arquitectónico desde un punto de vista arqueológico. El conocimiento de la existencia de restos de época antigua, en especial las del recinto de culto imperial, y la necesidad de obtener los necesarios datos históricos han permitido empezar los trabajos arqueológicos en diferentes puntos de la seo, en especial en la zona del claustro-casas de los Canónigos.

La catedral de Tarragona tiene la categoría de Monumento Histórico Artístico (RO de 3 de abril de 1905, Gaceta de Madrid de 12 de abril de 1905) y la ciudad de Tarragona es Conjunto Histórico Artístico desde 1966 (Decreto 652/1966 de 10 de marzo, BOE de 22 de marzo de 1966). Además, la existencia de estructuras que, como ya hemos citado pertenecen al recinto de culto flavio, hace que éstas sean incluidas en el catálogo de monumentos de la declaración de Tarraco como Patrimonio Mundial de la Humanidad (año 2000).

Las excavaciones arqueológicas llevadas a cabo alrededor del ala norte del claustro de la catedral de Tarragona, derivadas de la necesidad de solucionar los graves problemas de humedades, han permitido estudiar una secuencia estratigráfica que en algunos de los puntos alcanzaba una potencia de nueve metros, y en una extensión que ultrapasa las dimensiones de este lado del claustro.

Con anterioridad, la catedral de Tarragona había sido objeto de diferentes trabajos arqueológicos, como los llevados a cabo en los años treinta por el Rvdo. Joan Serra Vilaró en la zona de Santa Tecla la Vieja o los que en los años cincuenta efectuó el profesor Sánchez Real en el patio del claustro, lugar donde en los años 80 Xavier Dupré volvió a realizar sondeos arqueológicos. Con el objetivo de profundizar en el conocimiento del recinto sagrado imperial el profesor Hauschild materializó diferentes campañas de estudio arquitectónico y de excavaciones.

\section{LAS PREEXISTENCIAS DE ÉPOCA ROMANA Y DE LA ANTIGÜEDAD TARDÍA}

Tarragona se extendió por la ladera meridional de la colina que llega a los ochenta metros de altitud sobre el nivel del mar. Esta especial orografía ha sido un elemento clave para 
entender la topografía urbana de la ciudad desde la Antigüedad. En la parte más alta, se estableció en época tardo-republicana la base militar y política de Roma durante la Segunda Guerra Púnica y la posterior conquista de Hispania. En época flavia (69-96 dC) este amplio espacio, de unas $18 \mathrm{Ha}$, fue ocupado por dos grandes plazas (la inferior de representación político-religiosa, y la superior un recinto presidido por el templo de culto imperial), y un circo, que formarían lo que se ha llamado la sede del Concilium Prouinciae Hispaniae Citerioris. En este mismo espacio se ubicó posteriormente parte de la ciudad visigótica de Tarragona y, siglos después, fue el punto de inicio de la reocupación medieval de la misma.

La plaza o terraza superior era una amplio espacio de 153 por 136 metros rodeado por un muro perimetral, el temenos, en el cual había una serie de aberturas cada siete metros y medio entre ejes, y un pórtico con columnas, los fustes de las cuales medirían unos cinco metros de altura. De este gran muro se conservan importantes vestigios, especialmente los de los lados norte y oeste del claustro de la catedral, que fueron reutilizados como parte de su cierre. En los lados mayores del pórtico había grandes arcos con exedras $\mathrm{u}$ hornacinas posiblemente destinadas a alojar estatuas de culto imperial.

En la antigüedad tardía estos espacios sufrieron una importante transformación, con el desmantelamiento parcial de las estructuras y la conversión en zona de hábitat, y en sede de los poderes político y religioso, en donde destacaría el episcopio.

De este modo puede observarse que, por ejemplo en la sede del Colegio de Arquitectos, se construyeron una serie de muros perpendiculares a los paramentos exteriores del temenos, que conjuntamente a diferentes hallazgos entre el claustro de la seo, cementerio, antigua hospital de Santa Tecla y calle de las Coques -inhumaciones, piezas de escultura decorativa, dos vertederos etc.- indican que una parte del antiguo recinto sagrado imperial ya se desmantela en el siglo $\mathrm{V}$, y en el VI es ocupado por la sede del episcopio visigótico, espacio que en la edad media se volvería a usar para la sede metropolitana y las dependencias del poder eclesiástico de la ciudad.

Desconocemos qué sucedería después de la conquista árabe-musulmana, hasta el punto de no estar clarificado si $\mathrm{Ta}$ rraco fue tomada de manera pacífica o violenta. Fuera como fuese, el obispo Próspero y sus diáconos Procopio y Pantaleón huyeron de la ciudad con las reliquias y libros litúrgicos.

Los trabajos del Plan Director en el área al norte del claustro han descubierto una parte importante del muro del temenos del recinto flavio. En esta zona se ha conservado una altura de muro de nueve metros y ha podido ser observada la técnica edilicia y los sistemas de drenaje de su pe- rímetro exterior, mediante un relleno de bloques megalíticos, sobrantes de obra y ripio, y un sistema de canales que conducían el agua pluvial. En concreto se ha podido estudiar el sistema constructivo: apertura de una gran zanja de cimentación en la roca, construcción del basamento del muro mediante sillares dispuestos a tizón y desbastados en la cara visible, y erección del muro con sillares de unos ochenta centímetros de grosor, dispuestos a tizón y sin unión de mortero. Se han podido observar los encajes de los ferrei fornices para su elevación mediante maquinaria, la unión casi perfecta de los sillares, sin uso de mortero y unas juntas verticales muy finas, hacen pensar en un serrado con las piezas presentadas in situ y su posterior encaje final. Por otro lado se ha podido apreciar que la cara del muro que mira al interior de la plaza fue alisada y perforada de forma muy regular con la intención de forrarla con un placado de mármol. En cambio, en el paramento exterior los sillares fueron labrados con un imponente almohadillado a punzón. En cuanto a la estructura de las fenestrae, se ha podido observar su construcción solidaria al muro, y una cuidadísima técnica en la disposición de sillares y dovelas, junto a un interesante sistema de descarga de tensiones mediante un arco adintelado y un gran sillar a la manera de dintel sobre la abertura.

Otro aspecto interesante es el relleno constructivo de la zanja de cimentación, con la deposición de grandes megalitos de roca calcárea, procedentes seguramente del rebaje de la zanja constructiva, y la constatación de tres niveles relacionados con la obra, el inferior que se asocia a la obra de cimentación, el intermedio con gran cantidad de esquirlas procedentes de la labra de los sillares, y el superior, con fragmentos de mármol procedentes del trabajo de las placas decorativas a pie de obra.

De gran interés ha sido el descubrimiento de un muro de la antigüedad tardía, construido con sillares reutilizados, unidos sin mortero, perpendicular al temenos, que ha de relacionarse con una cisterna que sellaba exteriormente una de las grandes fenestrae del muro flavio. Ésta tiene unas dimensiones de $7 \quad 7$ metros aproximadamente y está cubierta por una bóveda de medio punto de opus caementicium.

La localización de estas dos estructuras es interesante porque muestran como en la antigüedad tardía la zona del antiguo recinto de culto imperial sufrió una importante transformación derivada de los cambios comportados por la oficialidad del Cristianismo, que conllevaron la creación de nuevos espacios de poder religioso y el desmantelamiento de los conjuntos edilicios paganos después del edicto de Teodosio y la promulgación de leyes que permitían desmontar los viejos templos. De este modo, la pérdida funcional del antiguo recinto imperial conllevó a que podía ser 


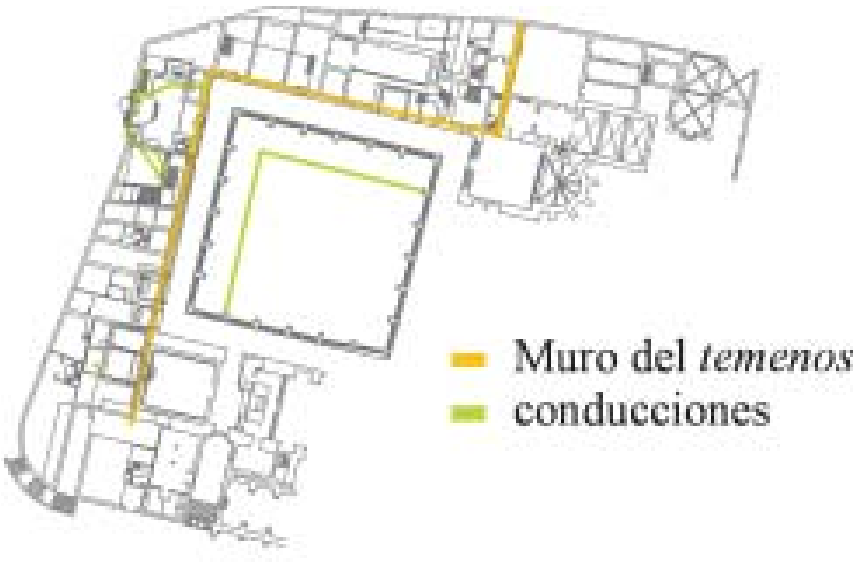

ÉPOCA FLAVIA

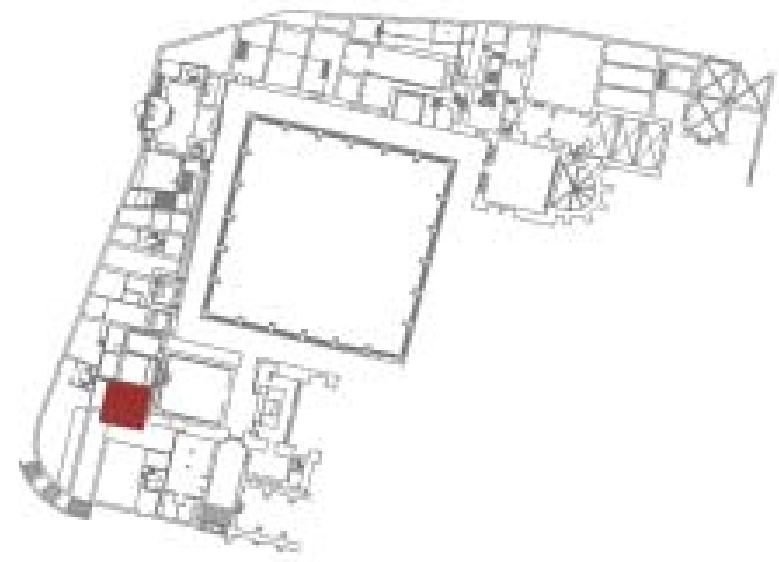

\section{ANTIGÜEDAD TARDÍA}

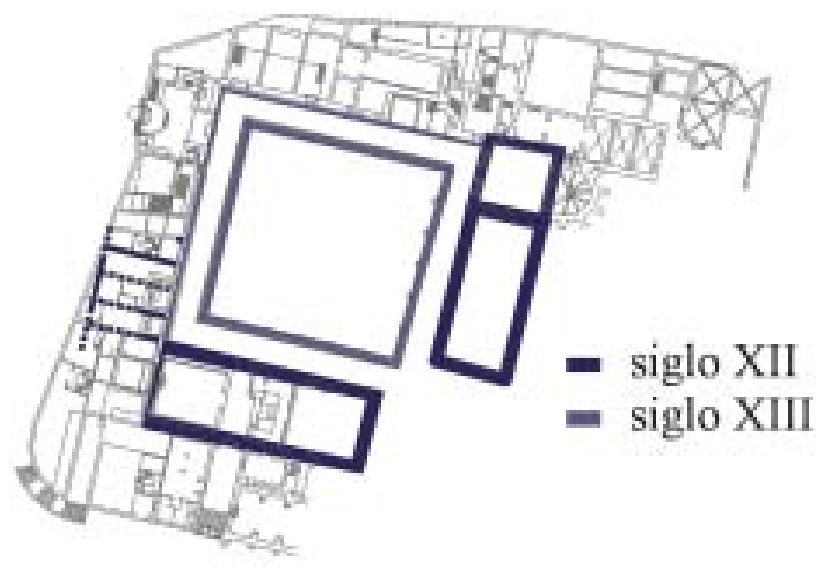

SIGLOS XII-XIII

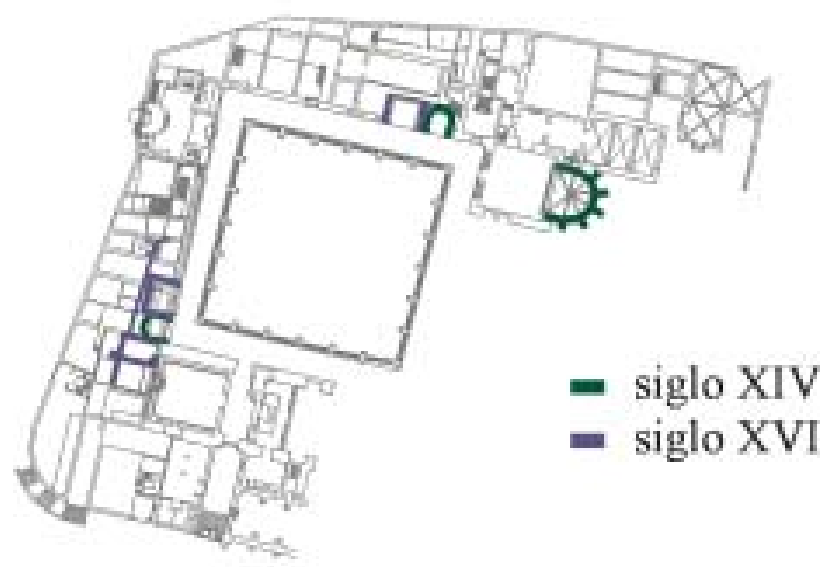

SIGLOS XIV-XVI

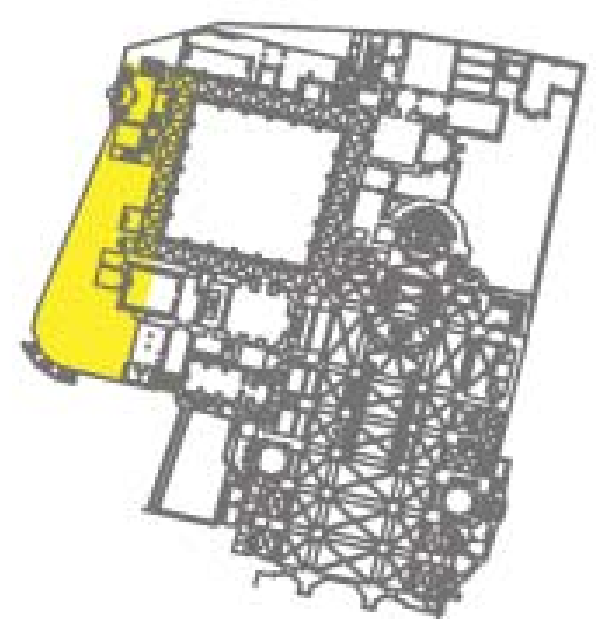

Fig. 1. Evolución de la zona del claustro de la catedral de Tarragona 


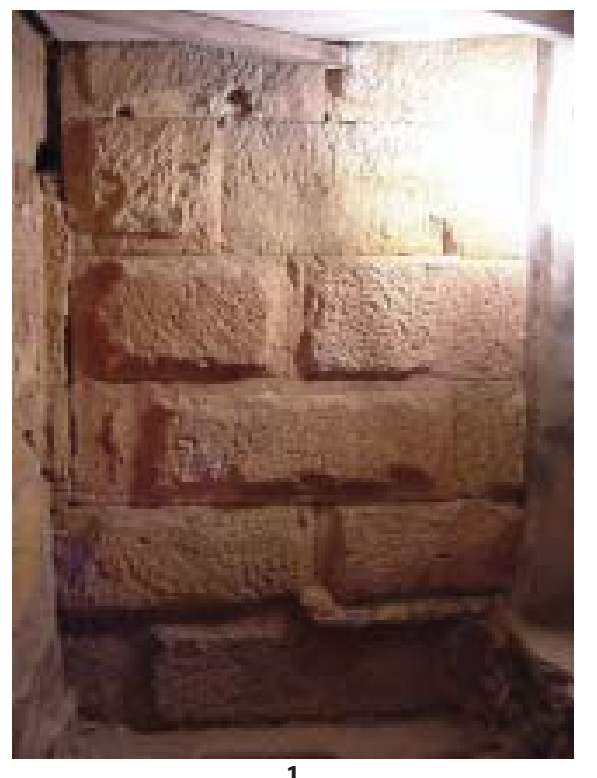

1

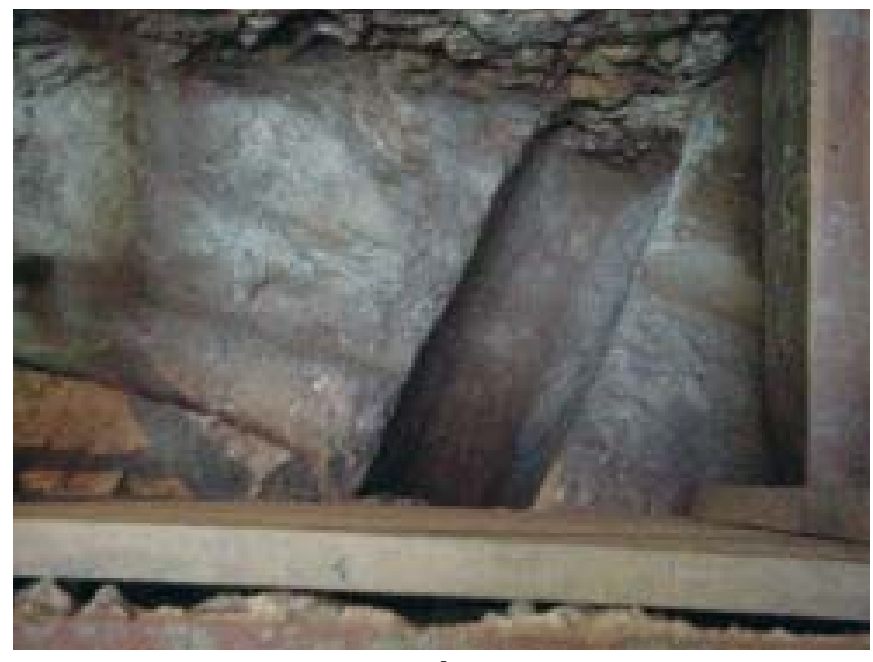

4

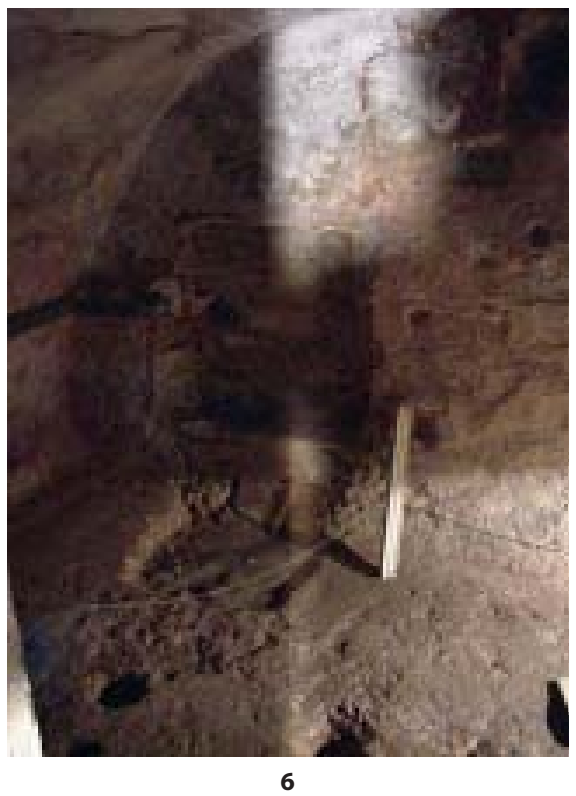

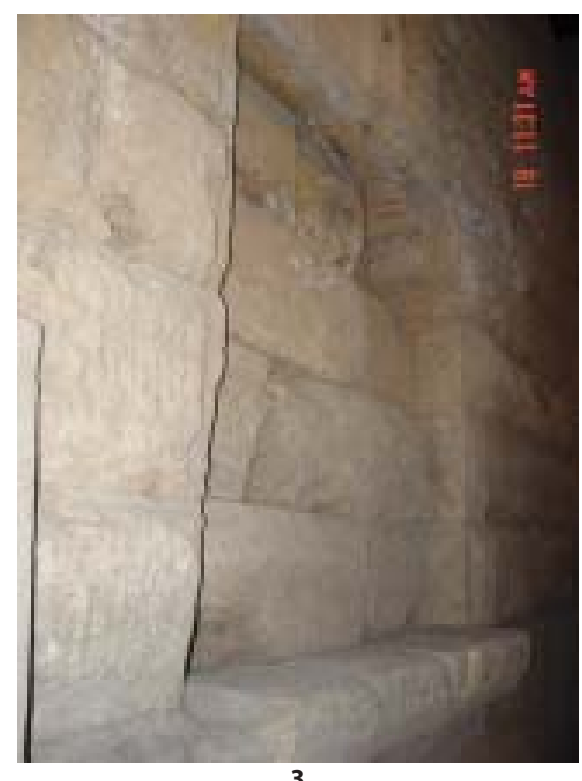

3
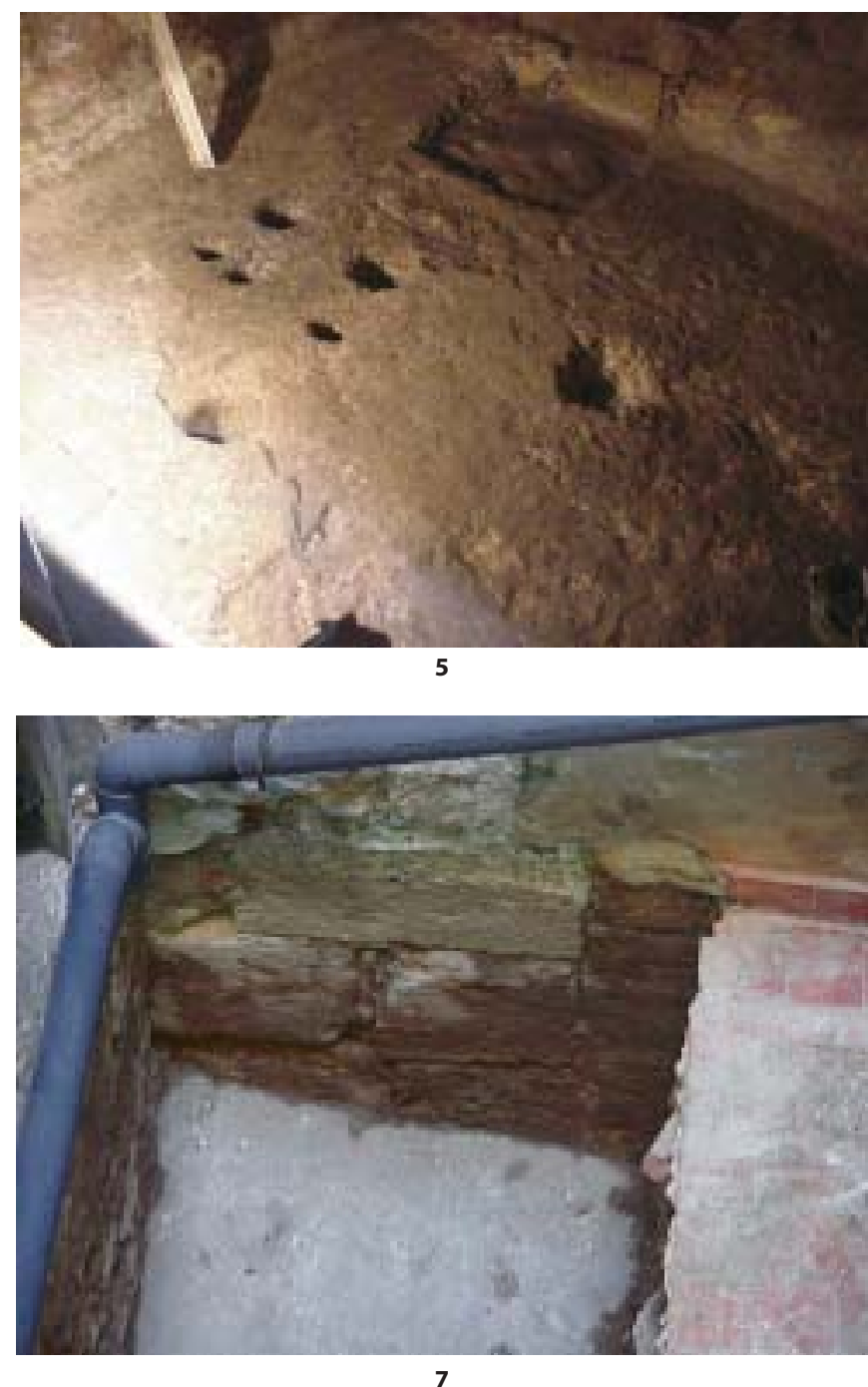

7 
desmantelado para poder adaptar el espacio al nuevo poder religioso, el episcopal.

Por otro lado la situación de la cisterna y del muro adosado al paramento exterior del muro flavio, recuerda las estructuras del mismo período que se localizaron en Colegio de Arquitectos (datadas a priori a finales del siglo V, para después situarlas en la primera mitad del siglo VI) en el lado opuesto y también al exterior de la plaza flavia. En este espacio se documentó una serie de aulas y una cisterna, construidas con sillares procedentes del antiguo recinto flavio. Se ha supuesto que estas construcciones formarían parte del episcopio de Terracona, y han de relacionarse con los hallazgos funerarios y de escultura arquitectónica localizados en las calles próximas.

Por otro lado, estas cisternas, junto a las localizadas en las plazas del Forum y del Rovellat muestran el cambio en el suministro hidráulico de época imperial, mediante acueductos principalmente, en la antigüedad tardía, con la recogida de las aguas pluviales en grandes depósitos.

Las excavaciones arqueológicas en el lado norte del claustro también han mostrado otros elementos a relacionar con esta profunda transformación de la zona. De este modo se ha detectado sobre los niveles arqueológicos de época flavia una fase que ha de datarse en la primera mitad del siglo VI, igual que los restos referidos del Colegio de Arquitectos, que ha demostrado el desmontaje de la decoración y pórtico del recinto sagrado, básicamente de mármoles de Luni-Carrara. Las dimensiones y tipología de los restos pétreos, principalmente fragmentos muy desmenuzados, muestran un claro proceso de reutilización de los materiales, como sería la extracción de las estrías de las columnas, para su uso en otras construcciones, quizás en los nuevos edificios de representación como el episcopio o la iglesia catedral, identificada con la Santa Jerusalén citada en el Codex Veronensis.

Nos situamos, pues, en un claro proceso urbanístico en el que las grandes construcciones imperiales que han perdido su uso, se transforman en los nuevos equipamien- tos eclesiásticos de Terracona. De esta manera parte de los muros del temenos se desmontan, conservándose aquellos tramos que se consideran aprovechables para las nuevas construcciones y urbanística.

Hay otro elemento que ha de tenerse en cuenta. La localización de dos vertederos en la zona del antigua recinto sagrado, uno debajo el actual Consejo Comarcal del Tarragonés, antiguo hospital de Santa Tecla, dentro del porticado del recinto sagrado; y el otro en el claustro de la seo, dentro de la antigua plaza flavia. Su descubrimiento indica la presencia de espacios de hábitat en su proximidad y la transformación del sistema de eliminación de residuos urbanos, ya en el siglo $\mathrm{V}$.

Nos encontramos ante un proceso puesto en marcha en el siglo $\mathrm{V}$ y que muestra que en el VI, después de la desaparición de la administración romana y del imperio, hay una transformación de estos antiguos espacios religiosos, quizás motivada por una planificación oficial de tipo episcopal con el traslado del primitivo episcopio desde el Francolí, al lado de la basílica martirial del obispo Fructuoso y sus diáconos, al antiguo espacio de prestigio religioso en época imperial.

La localización de estas estructuras perpendiculares al temenos, pero de otra envergadura arquitectónica, y asociadas a cisternas, así como en las excavaciones del norte del claustro de la catedral como del Colegio de Arquitectos, plantean una serie de cuestiones que por el momento no pueden ser resueltas de manera satisfactoria. Cabe pensar si nos encontramos ante una planificación urbanística que ocupa la periferia del recinto sagrado o también la antigua plaza de la terraza superior donde hemos de ubicar la sede episcopal. Por otro lado, ¿cuál sería la extensión de los equipamientos episcopales? ¿qué parte o partes de la plaza flavia era ocupada? La impresión es que la parte este, donde se encuentra la mayor concentración de hallazgos, era las más densamente ocupada, pero esta idea se basa en una información desigual del recinto superior en época tardo-antigua.

Fig. 2. Aparejos constructivos de la catedral de Tarragona:

Época flavia: construcción del temenos del recinto sagrado (desmonte del terreno, cimentación de sillares a tizón, muros de opus quadratum almohadillado y ventanas con alféizar moldurado, decoración con mármol de Luni-Carrara (placados en muro), drenajes basados en canales en la roca y bloques ciclópeos y sillares rehusados al pie de la cimentación). Fotografía 1: muro de opus quadratum; fotografía 2: fenestra en el muro (Museu Diocesano); fotografía 3: fenestra extradosada por el muro románico del claustro; 4: canal de drenaje.

Antigüedad tardía: operaciones de desmontaje del temenos del recinto sagrado mediante el desmonte del muro y expolio de material marmóreo; construcción de estructuras de sillares reutilizados perpendiculares al temenos y construcción de cisterna de opus caementicium y revoco de opus signinum, con cubierta en bóveda de cañón. Fotografía 5: pavimento de opus signinum de cisterna; fotografía 6: detalle del pavimento y bóveda de la cisterna; fotografía 7: muro de sillares reutilizados. 

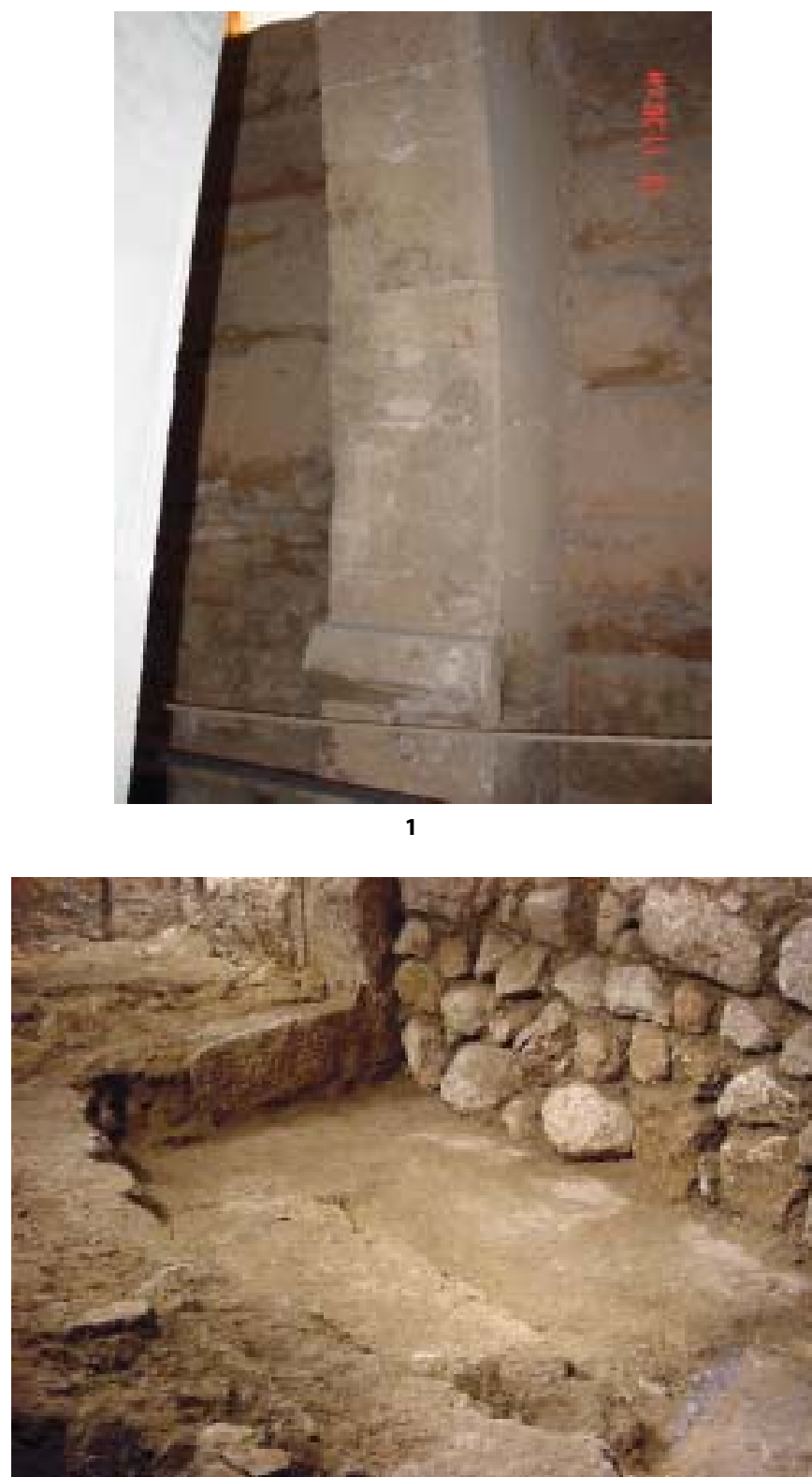

3

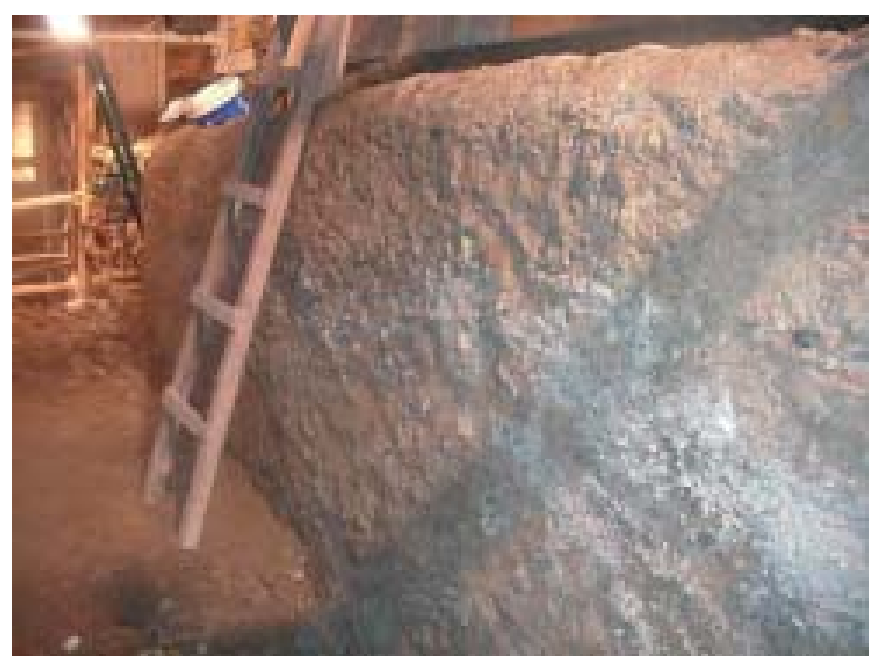

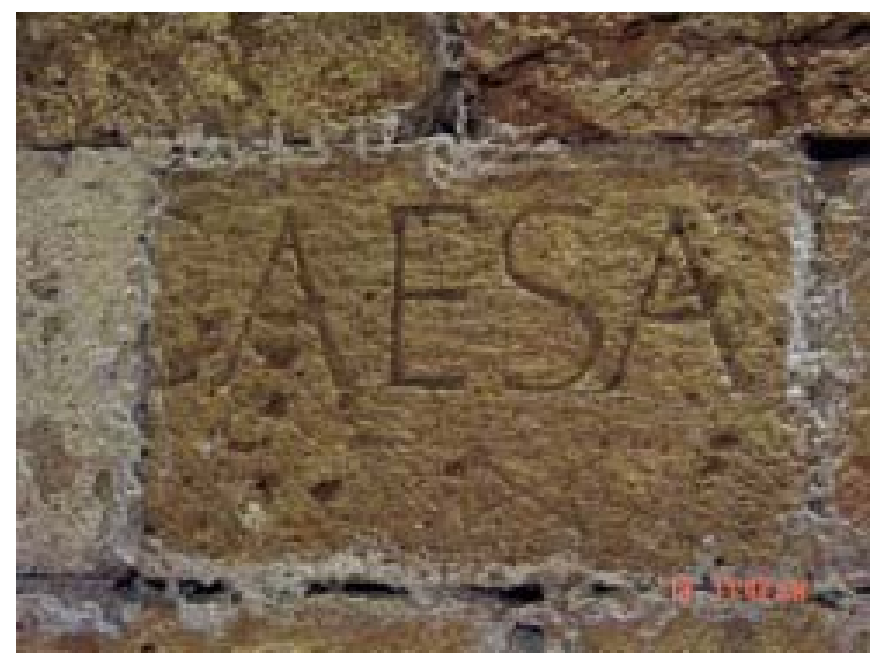
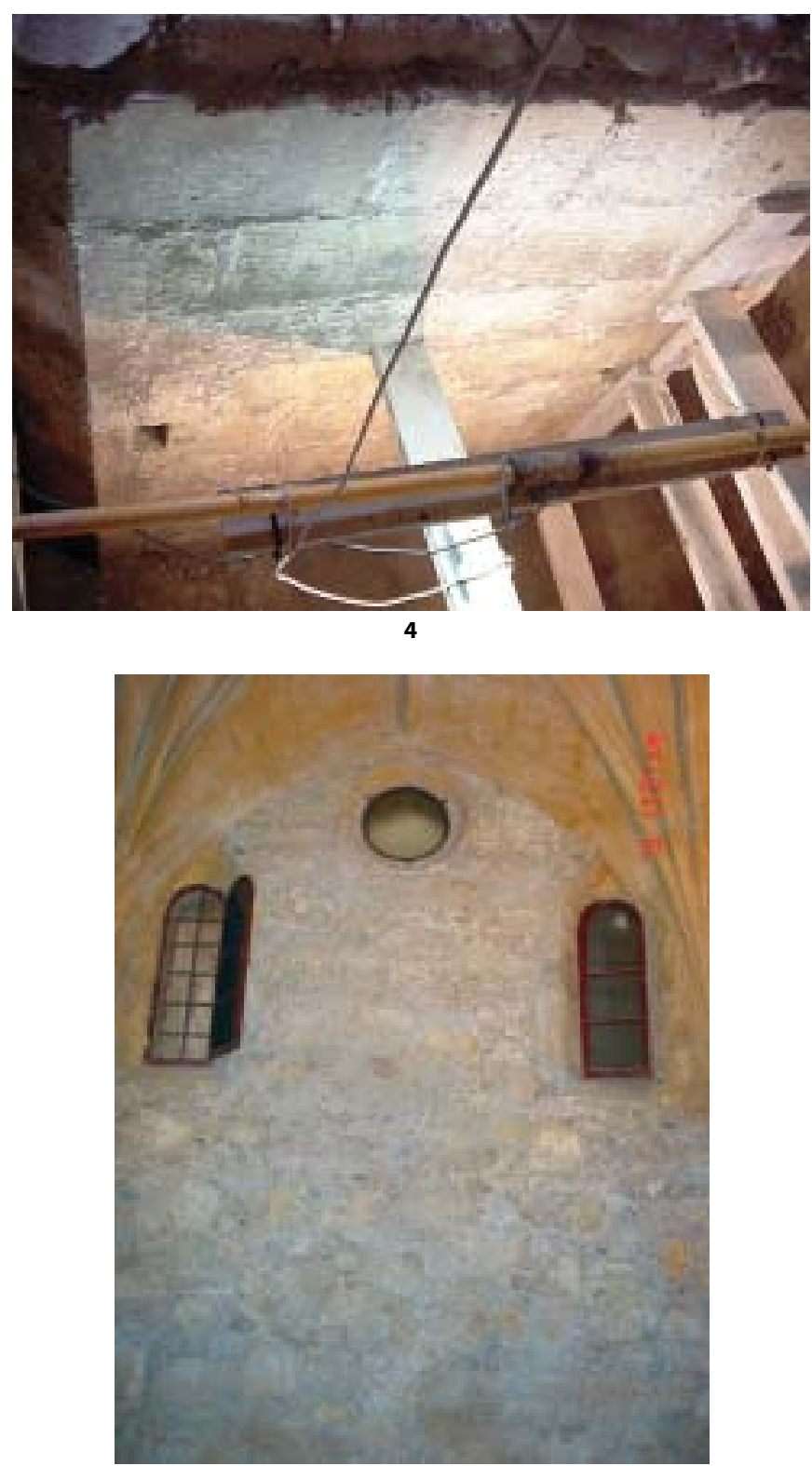

6 


\section{LA CONSTRUCCIÓN DE LA CATEDRAL MEDIEVAL}

La invasión árabe-musulmana de la península ibérica comportó un grave trastorno para Terracona. El éxodo de la élite eclesiástica, lejos de ser un hecho puntual, junto al cambio de la situación geopolítica de la zona, en que la vieja ciudad había perdido peso a favor de Barcino durante los siglos VI y VII, situarían a Tarraco en vía muerta. ¿Qué ocurre en la ciudad entre los siglos VIII y XI? ¿Estaba deshabitada o existía población?

En la catedral se conserva una importante pieza islámica, el llamado mirhab, que ha sido relacionada con la mezquita aljama de Tarraqūna. Pero parece ser que es una pieza procedente de Madinat al-Zahra, por lo que esta definición deja en suspenso, otra vez, la cuestión de Tarragona entre los siglos VIII y la conquista feudal.

En el año 1091 se restaura la sede episcopal, con el obispo de Vic Berenguer Seniofred de Lluçà, aunque ha de esperarse hasta el siglo XII para ver una ocupación definitiva de la vieja ciudad visigótica: en 1118 se otorga al obispo de Barcelona Oleguer Bonestruga, y el papa Gelasio II lo designa arzobispo de Tarragona, mientras que Roberto Bordet empieza la colonización de la ciudad y del territorio. Aún así, ha de llegar el año 1145, para tener un arzobispo establecido definitivamente, que fue Bernardo Tort. El 1153-1154 se conquista Siurana, último reducto islámico en Cataluña y en el mismo año se firma una bula con la primera lista de parroquias de la diócesis de Tarragona y el arzobispo dota la canónica de la catedral.

El antiguo episcopio visigótico reocupado sería probablemente un conjunto en mal estado y poco funcional para las necesidades del nuevo arzobispado, restaurado para liberar la iglesia catalana de las ligaduras con la sede de Narbona. De este modo la restauración de la cátedra necesita de la reocupación de los antiguos espacios litúrgicos y religiosos, no sólo de la iglesia madre visigótica y del episcopio con la nueva catedral y canóniga, sino también de la iglesia martirial del anfiteatro con Santa María del Milagro, la zona funeraria del Francolí, con al menos dos iglesias en la antigüedad tardía, con Santa Magdalena de Bell-Lloc, o la zona funeraria de la colina de Mas Rimbau-Mas Mallol con el templo de San Pedro Sacelades.

El año 1154 Bernat Tort establece la canóniga catedralicia, y la dota de un monasterio en forma de fortaleza, según reza el documento, y del equipamiento necesario: bodegas, graneros, dormitorio, cocina y sala capitular... Esta fecha puede entenderse como el génesis del nuevo conjunto arzobispal, con la construcción de los espacios necesarios para la vida comunitaria de la canónica establecida, y el principio de las obras de la nueva iglesia, ya que seguramente las dimensiones y el estado del viejo templo visigótico no ofrecían las condiciones necesarias para la sede recuperada, de manera que en el año 1167 ya se menta una donación para las obras del nuevo templo en el testamento de Pedro de Queralt.

El monasterio se articula alrededor de un claustro situada en el ángulo noroeste del antiguo temenos imperial, en excelente estado de conservación quizás por ser usado como parte integrante del episcopio visigótico. Los condicionantes topográficos y el deseo de usar los muros flavios de opus quadratum, provoca que el claustro quede situado entre el transepto y la cabecera de la nueva iglesia catedral, cuando usualmente este espacio se localiza entre éste y la nave.

Las excavaciones realizadas han permitido localizar en el lado norte del claustro un gran edificio, otorgándole una cronología de segunda mitad del siglo XII. Esta construcción aprovecharía como cierre meridional el muro del temenos romano, y usaría el corredor de servicio coetáneo al muro abierto en la roca natural en época imperial. Como límite occidental se encontraría la cisterna y el muro de sillares tardo-romanos citados anteriormente. Esta estancia, de dimensiones similares al refectorio de los canónigos del siglo XII, estaba dividida en su interior por arcos diafragma, de los cuales se conserva uno prácticamente entero, y parte

Fig. 3. Aparejos constructivos de la catedral de Tarragona:

Siglo XII: Inicio de la construcción de la catedral y canónica, introducción del románico, aprovechamiento muros romanos; construcción de refectorio con muros de sillares reutilizados y bóveda de cañón apuntado; construcción de sala con arcos diafragma ligeramente apuntados; extradosado del muro del temenos para sujeción de bóvedas del claustro, aparición de las primeras marcas de cantero; reutilización de fenestrae como accesos. Fotografía 1: arco apuntado; fotografía 2: inscripción romana reutilizada en el muro del refectorio; fotografía 3: escalera de mortero al pie de fenestra reutilizada.

Siglos XIV-XIV: construcción de capillas aprovechando las aberturas de las fenestrae; amortización de estancias canonicales, introducción de los estilos gótico y renacentista, a partir del siglo xVI, sistema de drenaje tras las capillas. Fotografía 4: capilla de Nuestra Señora de las Nieves, de sillares con marcas de picapedrero y cubierta de mortero enfoscado; fotografía 5: muro de drenaje tras las capillas de las Nieves y San Salvador; fotografía 6: detalle del muro de la capilla de la cofradía de Santa Tecla. 
de tres más. La fachada norte dispondría una serie de aberturas que recuerdan al sistema de arcos que pueden verse en el dormitorio de los monjes del monasterio de Santas Creus. Por lo que se refiere a los accesos a esta estancia parece verosímil que se usasen algunas de las fenestrae del muro del temenos, como se ha constatado durante los trabajos de excavación. La intervención ha permitido estudiar una de estas aberturas imperiales a la que se le rebajó el antepecho moldurado original para realizar un paso hacia una escalera cortada en los niveles tardo-romanos y rematada con una capa de mortero de cal, que servía para llegar al nivel de la nave, hecho también de un pavimento de cal de poco grosor, y diferentes niveles de tierra compactada. La cara interior de la fenestra se reforzó con un capialzado del que se conservan los encajes de los salmeres. Desconocemos si el resto de aberturas del muro flavio tendrían la misma funcionalidad, ya que, o han sido abiertas por vanos de época medieval, o por la apertura de capillas. Un hecho interesante es que la cubierta del claustro con bóvedas de crucería, que se data entre finales del siglo XII y principios del XIII, necesitó del extradosado del muro del temenos (que no llega al metro de grosor) por lo que se condenaron las fenestrae, incluida la aprovechada como puerta de la nave, hecho que establece un claro terminus ante quem para la construcción de esta sala.

Hasta el momento no puede definirse la funcionalidad de esta estancia, aunque ha de relacionarse con las diversas piezas que se localizan en el claustro de la catedral como son el refectorio, sala capitular y sacristía.

Los arcos diafragmas que cubrían la nave se construyeron con un ligero alabeado respecto al muro del temenos, y se utilizaron sillares del recinto flavio convenientemente recortados y acabados, algunos de ellos con marcas de picapedrero. Se pudo excavar su cimentación, consistente en una potente zanja que llegaba a la roca, dentro de la cual se levantó el arco con un ligero ensanchamiento en la base en forma de banqueta que apoya en la roca y en la cimentación de sillares del muro romano. El trabajo de las dovelas es esmerado, y puede observarse cómo las piezas tienen la misma rosca y el extradós bien acabado, detalles que ya no se observan en arcos de cronología posterior.

Los trabajos arqueológicos también han permitido el estudio de parte de la construcción del refectorio (siglo XII), pudiéndose observar otra vez la reutilización de sillares de época romana. De esta forma los paramentos de esta cronología en la catedral de Tarragona muestran un despiece muy grande, pudiendo ver fragmentos de inscripción monumental romana reaprovechadas entre las piezas.

La nave del siglo XII padeció una importante transformación a principios del siglo XIV, en el momento de la construcción de la capilla de Nuestra Señora de las Nieves en el ángulo noroeste del claustro, en el lugar de una de las fenestrae. Se trata de una pequeña capilla gótica de planta poligonal, de sillares de dimensiones menores que los de las construcciones del siglo XII. Son piezas que pueden ser movidas con la fuerza de un solo hombre, que fueron dispuestas a juntas encontradas, y en la cara exterior de la capilla se ha podido constatar un acabado a junta llena con poco esmero. La excavación ha mostrado que la capilla fue rematada con terraza a una vertiente, hecho que lleva a pensar que en el momento de construcción de la misma quizás la nave de arcos diafragma se encontraba en desuso y desprovista de cubierta. Dicha terraza es una obra de mortero de cal enlucido, a manera de terraza, con sencillos rebosaderos formados de sendos fragmentos de teja actuando de canal en los ángulos de la capilla. Esta solución de la cubierta se observa en otros puntos de la catedral, como en la sacristía, la sala capitular o en las naves laterales del templo.

\section{LAS REFORMAS DE ÉPOCA MODERNA Y CONTEMPORÁNEA}

La dinámica constructiva de capillas en el claustro continúa en el siglo XVI. De este modo en el año 1553, el matrimonio de Nicolás Albanell y Ángela subvencionó la construcción de la capilla de San Salvador, de estilo renacentista, ubicada al lado de la de las Nieves. Se trata de una pieza de planta rectangular cubierta con bóveda de medio punto, de la que se ha podido estudiar la cara exterior, formada por un paramento de sillares de pequeñas dimensiones, acabados a gradina y muchos de ellos con marcas de picapedrero, y remate moldurado de la cornisa. La cubierta es una terraza casi plana hecha con mortero de cal, de la misma manera que la capilla de las Nieves.

En el mismo siglo, pero de estilo gótico tardío, se levantó la capilla de cofradía de Santa Tecla, en la cabecera del refectorio de los canónigos, ocupando parte de la antigua nave del siglo XII. Es una construcción de muros de mampostería o aprovechando el paramento de sillares tardo-romano antes citado, con contrafuertes en los ángulos, sobre los que descansa una bóveda estrellada. Las ventanas son de medio punto y la puerta es un arco conopial abierto en el muro del temenos, en el lugar donde había una fenestra.

La construcción de las capillas de las Nieves, San Salvador y de la cofradía de Santa Tecla, muestran una importante transformación de la zona norte del claustro de la catedral, con la amortización de la nave del siglo XII, quedando al descubierto, ya que poco después de levantarse las capillas de San Salvador y la cofradía de Santa Tecla se construyó un sistema de drenaje y contención de tierras consistente en un 
muro de mampostería y un corredor de servicio con pavimento de mortero de cal en la parte posterior de las capillas de San Salvador y de la Nuestra Señora de las Nieves.

El año 1580 el Cabildo cedió parte del refectorio al arzobispo Agustín para que fuera habilitado como capilla del Santísimo, de manera que este antiguo espacio monacal quedó cortado por la mitad. Quizás en estos momentos es cuando se establece comunicación entre el refectorio y la cisterna tardo-romana. El estudio de ésta y la observación del paramento adyacente por la cara este, que corresponde al muro del temenos, muestra una serie de elementos que debieran ser explicados satisfactoriamente. En primer lugar nos encontramos con dos aberturas cegadas en época indeterminada que implican su cambio de uso, de cisterna a estancia practicable. En segunda lugar, un rebaje en el muro del temenos en forma de arcosolio da paso a una pequeña abertura a la manera de un portillo de torno.

Por otro lado, en el interior hemos podido observar una serie de perforaciones en el pavimento de opus signinum tardo-romano, preparadas para sustentar estructuras de madera que podrían ser bancos de trabajo. También se detectaron evidencias de combustión.

Estos elementos hacen pensar que la cisterna pudo ser reaprovechada como cocina a relacionar con el refectorio de los Canónigos. Pero, ¿̇cuándo? El hecho es que la estratigrafía que la cubre data de finales del siglo XIX - principios del XX, momento en que se construyen las actuales casas de los Canónigos.

La última fase constructiva que hemos documentado es el cubrimiento con un potente nivel de tierras de la mayoría de estructuras, ya que la zona sufre una importante transformación debida a la construcción de las nuevas casas de los Canónigos siguiendo el proyecto de los arquitectos Elías Rogent y Augusto Font i Carrera. Estas obras también comportaron el desmontaje de construcciones de época medieval y moderna, así como parte de la cisterna tardo-romana, y el reaprovechamiento de sillares de época flavia en cimentaciones de los nuevos edificios.

\section{Bibliografia}

AquiluÉ X., 1993, La seu del Col.legi d'Arquitectes. Una intervenció arqueològica en el centre històric de Tarragona, Tarragona.

Aquilué X., Dupré X., Massó J., Ruiz De Arbulo J., 1991, Tàrraco. Guia Arqueològica, Tarragona.

CAPDevila S., 1935, La Seu de Tarragona, Barcelona.

Catalunya Romànica, vol. XXI: El Tarragonès, el Baix Camp, l'Alt Camp, el Priorat, la Conca de Barberà. Barcelona (1995).

Del romà al romànic. Història, art i cultura de la Tarraconense mediterrània entre els segles IV $i X$. Barcelona (1999).

DUPRÉ X., PÀMIES, A. M., 1986-87, Intervenció arqueològica al carrer de Santa Tecla de Tarragona, Butlletí Arqueològic, núm.8-9, p. 229-234.
Figuerola J., GaVAldÃ J., 2000, Plan director de la catedral de Tarragona, Ars Sacra. Revista del Patrimonio cultural de la Iglesia, núm. 16, p. 107-123.

Figuerola J., Gavaldà J., Menchon J., Teixell I., Muñoz A., MaCIAS J. M., 2002, La catedral de Tarragona. Obres de restauració i treball arqueològic. Lambard. Estudis d'art medieval, vol. XIV, Barcelona, p. $75-107$.

HAUSCHILD T., 1983, Arquitectura romana de Tarragona, Tarragona.

HAusChild T., 1992, Hallazgos de la época visigoda en la parte alta de Tarragona, III Reunió d'Arqueologia Cristiana Hispánica, Maó 1988, Barcelona, p. 151-156.

HAusCHild T., 1992, Los hallazgos romanos de mármol en la Parte Alta de Tarragona, Butlletí Arqueològic, núm. 14, p. 107-135.

HAUSCHILD T., 1995, La intervención arqueológica en la capilla de Nuestra Señora del Claustro y la recuperación del muro romano junto a la capilla, en PAGÈs F., Restauració de la capella de la Mare de Déu del Claustre de la Catedral de Tarragona, Tarragona, p. 61-72.

HAUSCHILD T., 1996, Bronzefunde aus einem westgotenzeitlichen grab neben der Kathedrale von Tarragona, Spania. Estudis d'Antiguitat tardana oferts en homenatge al professor Pere de Palol, Barcelona.

MaCias J. M., 2000, Tarraco en la Antigüedad Tardía: un proceso simultáneo de transformación urbana e ideológica, Los orígenes del Cristianismo en Valencia y su entorno, Grandes Temas Arqueológicos 2, València, p. 259-271.

MAR R. [a cura de.], 1993, Els monuments provincials de Tàrraco. Noves aportacions al seu coneixement, Documents d'Arqueologia Clàssica 1, Tarragona.

Menchon J., Macias J. M., Muñoz A., 1994, Aproximació al procés transformador de la ciutat de Tàrraco. Del Baix Imperi a l'Edat Mitjana, Pyrenae núm. 25, p. 225-243.

Menchon J., Teixell I., Muñoz A., Macias J. M., 2003, Excavacions arqueológiques a la catedral de Tarragona (2000-2002), II Congrés d'arqueologia medieval i moderna de Catalunya. Sant Cugat del Vallès 18-21 d'abril de 2002. Acts. Barcelona, ACRAM, vol. I, p. 121-128.

Menchon J., Teixell I., Muñoz A., Macias J. M., (e.p), La catedral de Tarragona: trabajos arqueológicos derivados del Plan Director, Jornadas sobre Catedrales. Alcalá de Henares 2002.

RAMON S., 1990, Nova opinió sobre l'emplaçament de la primitiva catedral de Tarragona, Quaderns d'Història Tarraconense IV, Tarragona, p. 37-49.

RIU E., 1987, L'arqueologia i la Tarragona feudal, Fòrum. Temes d'Història i Arqueologia tarragonines, núm. 7.

RÜGeR C. B., 1968, Römische Keramik aus dem Kreuzgang der Kathedrale von Tarragona, Madrider Mitteilungen núm 9, p. 237-258.

SÁNCHEZ REAL J., 1969, Exploración arqueológica en el jardín de la catedral de Tarragona, Madrider Mitteilungen núm 10, p. 276-296.

SÁNCHEZ REAL J., 1988-89, El método en la arqueología tarraconense 2. Las construcciones monumentales de la Parte Alta. II.A) La zona "sagrada", Butlletí Arqueològic, núm. 10-11, p. 79-115.

SÁNCHEZ REAL J., 1990, El método en la arqueología tarraconense. Las construcciones monumentales de la parte alta. II.B) El Foro, Butlleti Arqueològic, núm. 12, p. 49-98.

SERRA VILARÓ J., 1960 Santa Tecla la Vieja. La primitiva catedral de Tarragona, Tarragona.

TED’A, 1989, El Foro Provincial de Tarraco, un complejo arquitectónico de época flavia, Archivo Español de Arqueología 62, núm 159-160, p. 141-191. 